\title{
Insight into the local environment of nickel in VSB-1 before and after calcination
}

Jianqiang Wang ${ }^{l}$, Zhendong Wang ${ }^{l}$, Zhenlong Jia ${ }^{l}$, Gen Meng ${ }^{l}$, Zhongqiang Xu ${ }^{l}$, Weimin Yang ${ }^{1}$, Anatoly I. Frenkel ${ }^{2}$ *

${ }^{1}$ Sinopec Shanghai Research Institute of Petrochemical Technology, Shanghai 201208, China

${ }^{2}$ Physics Department, Yeshiva University, New York, NY 10016, United States

\section{"Corresponding authors:}

\section{Weimin Yang}

Shanghai Research Institute of Petrochemical Technology

Shanghai 201208

P. R. China

E-mail: yangwm.sshy@ sinopec.com

Telephone: (+86-21) 68462197-7122

Fax: (+86-21) 68462283

\section{Anatoly I. Frenkel}

Department of Physics

Yeshiva University

New York 10016

The United States of America

E-mail: Anatoly.frenkel@yu.edu

Telephone: (+1-212) 3407827

Fax: (+1-212) 3407868 


\begin{abstract}
The local environment of nickel in VSB-1, a nanoporous nickel phosphate material, was systematically investigated by a combination of X-ray absorption spectroscopy and multiple complementary techniques before and after calcination. A considerable unit cell shrinkage observed in VSB-1 after calcination is explained by the loss of $\mathrm{F}^{-}$ions and the corresponding changes in the nickel environment.
\end{abstract}

Keywords: VSB-1; Nickel phosphate; XAFS; TGA/DTG-DSC-MS; UV-vis-NIR. 


\section{Introduction}

Since the nanoporous material of nickel phosphate, VSB-1 (Versailles-Santa Barbara) with the chemical composition of $\mathrm{Ni}_{18}\left(\mathrm{HPO}_{4}\right)_{14}(\mathrm{OH})_{3} \mathrm{~F}_{9}\left(\mathrm{H}_{3} \mathrm{O}^{+}\right.$, $\left.\mathrm{NH}_{4}{ }^{+}\right)_{4} \cdot 12 \mathrm{H}_{2} \mathrm{O}$,[1] was synthesized, it has attracted much attention in many fields of materials: catalysts,[2-10] flame retardants,[11, 12] optical devices,[13, 14] hydrogen storage.[15] High thermal stability gives VSB-1 potential prospects in many application areas that require porosity. To release the pore system for removal of water molecules, hydroxyl groups and amine moieties, the calcination process has to be done in air.

Thermodiffractometry study of VSB-1 showed the structure of the parent phase is clearly sustained up to $550^{\circ} \mathrm{C}$.[1] However, the intensity of VSB-1 gradually decreased as the calcination temperature exceeded $400^{\circ} \mathrm{C}$. The structure finally collapsed to form an amorphous phase at $750^{\circ} \mathrm{C}$ and then recrystallized to form condensed $\mathrm{Ni}_{3}\left(\mathrm{PO}_{4}\right)_{2}$ at $1150^{\circ} \mathrm{C}$.[1] Meanwhile, thermogravimetric analysis[1] revealed the loss of water molecules, amine moieties and hydroxyl groups as the temperature increased. Additionally, $\mathrm{F}^{-}$ions was found to be necessary for the formation of VSB-1,[10] and only the synthesis of condensed nickel phosphate $\mathrm{Ni}_{12}\left(\mathrm{HPO}_{4}\right)_{6}\left(\mathrm{PO}_{4}\right)_{2}(\mathrm{OH})_{6}$ was reported without the presence of $\mathrm{F}^{-}$ions.[10] Nevertheless, to the best of our knowledge, the loss of $\mathrm{F}^{-}$ions during calcination was not investigated, nor was the role of $\mathrm{F}^{-}$ions in VSB-1 structure stability. The local environments of nickel before and after calcination, together with the loss of $\mathrm{F}$ ions during calcination, are also worthy of investigation. 
In this investigation, nanoporous VSB-1 was synthesized and characterized by XRD, TEM and UV-vis-NIR. Then, TG-DSC-MS analysis was performed on VSB-1(As-synthesized) to find the loss of $\mathrm{F}^{-}$ions. X-ray absorption spectroscopy (XAS)[16] was employed to study the local atomic environments of VSB-1 before and after calcination. Combined with the X-ray absorption near-edge structure spectroscopy (XANES) and extended X-ray absorption fine structure (EXAFS) analyses of VSB-1 at nickel K-edge, the changes in the chemical state and local environment of nickel were obtained and interpreted.

\section{Experimental}

\subsection{Materials synthesis}

VSB-1 was synthesized using $\mathrm{NiCl}_{2} \cdot 6 \mathrm{H}_{2} \mathrm{O}, \mathrm{H}_{3} \mathrm{PO}_{4}, \mathrm{NH}_{4} \mathrm{~F}$ and $\mathrm{H}_{2} \mathrm{O}$ as starting materials following the formula of Jhung et al.[17] by a traditional hydrothermal process instead of the fast crystallization under microwave irradiation. In a typical run, $\mathrm{NiCl}_{2} \cdot 6 \mathrm{H}_{2} \mathrm{O}$ was first dissolved in deionized water, into which $\mathrm{H}_{3} \mathrm{PO}_{4}$ was then added. After the mixture was stirred at room temperature for $30 \mathrm{~min}, \mathrm{NH}_{4} \mathrm{~F}$ was added to adjust the $\mathrm{pH}$ value to 2.5 under vigorous stirring, resulting in a green solution with chemical composition of $1 \mathrm{NiCl}_{2} \cdot 6 \mathrm{H}_{2} \mathrm{O}: 1 \mathrm{H}_{3} \mathrm{PO}_{4}: 2.5 \mathrm{NH}_{4} \mathrm{~F}: 100 \mathrm{H}_{2} \mathrm{O}$. The obtained reaction mixture was sealed in a $100 \mathrm{~mL}$ Teflon-lined stainless-steel autoclave at $180^{\circ} \mathrm{C}$ for $20 \mathrm{~h}$ under autogenous pressure. The solid products were filtered, washed with deionized water, dried over night at $80^{\circ} \mathrm{C}$, finally calcined at $450^{\circ} \mathrm{C}$ in air for $6 \mathrm{~h}$. The samples before and after calcination were denoted as VSB-1(As-synthesized) and VSB-1(Calcined), separately.

\subsection{Characterizations}

The crystalline structures of the materials were evaluated by X-ray powder diffraction at the Beamline X14A $(\lambda=0.7793584 \AA$, the sample was loaded into a 0.3 mm thin-wall quartz capillary) of the National Synchrotron Light Source at 
Brookhaven National Laboratory. Transmission Electron Microscopy (TEM) images were captured on a Tecnai G2 T20 S-Twin microscope operating at an acceleration voltage of $200 \mathrm{kV}$ (Conducted in Sinopec SRIPT). The TG/DSC/MS investigations (Conducted in Sinopec SRIPT) were carried out in air (sample weight, $38 \mathrm{mg}$; air flowrate, $40 \mathrm{~mL} / \mathrm{min}$ ) using a Simultaneous Thermal Analyzer STA 449F3 (for TG/DSC) coupled with a Quadrupole Mass Spectrometer QMS 403 (Netzsch). The temperature range was from $30^{\circ} \mathrm{C}$ to $850^{\circ} \mathrm{C}$ at a rate of $10^{\circ} \mathrm{C} / \mathrm{min}$. The vacuum in the quadrupole MS was $10^{-4} \mathrm{~Pa}$. The multiple ion detector (MID) mode was used in the MS measurements. UV-vis-NIR spectra were recorded on a Varian Cary 5000 UV-vis-NIR spectrophotometer (Conducted in Sinopec SRIPT) at ambient conditions against $\mathrm{BaSO}_{4}$ reference in reflectance mode. Chemical analysis of the VSB-1 samples was performed by both Inductively Coupled Plasma-Atomic Emission Spectrometry (ICP-AES, conducted in Sinopec SRIPT) and Fluoride ion selective electrode (FISE, conducted in Sinopec SRIPT).

\section{$2.3 X$-ray absorption measurements}

Sample of VSB-1 before and after calcination were pressurized to pellets using a hydraulic press. Nickel K-edge XAS measurements were conducted on the beamline X19A at NSLS. Harmonic rejection was achieved by detuning the incoming beam by $30 \%$ for $\mathrm{Ni}$ K-edge. The spectra of the nickel K-edge were aligned using the simultaneously collected $\mathrm{Ni}$ foil standard spectra, and the multiple scans under identical conditions were merged to improve the signal-to-noise ratio.

\subsection{Data Analysis}

Data processing and analysis were performed using the IFEFFIT package.[18, 19] The background subtraction of the absorption edge to yield the EXAFS oscillations were performed using the AUTOBK code which implements cubic spline interpolation with an adjustable frequency cutoff to fit the background function.[20] Standard procedures were followed for background subtraction, normalization, and extraction of XAFS functions $\chi(k)$. Fourier transformation of $k^{2}$-weighted $\chi(k)$ function gives a pseudo-radial distribution function. The spectra were fitted in $\mathrm{R}$-space by varying several adjustable parameters: coordination number $(\mathrm{N}$, the 
number of atoms in a shell about the absorbing atom), the photoelectron half-path length ( $R$, the distance to that shell), the correction to the threshold energy $\left(\Delta \mathrm{E}_{0}\right)$, and the EXAFS Debye-Waller factor $\left(\sigma^{2}\right.$, the mean-square displacement of the distance between the absorbing atom and the backscattering atoms for a single scattering path of photoelectron). The passive electron reduction factor $\left(S_{0}^{2}\right)$, was obtained from the measurement of bulk $\mathrm{NiO}$ and fixed in the analysis of $\mathrm{Ni}$ catalysts. The photoelectron amplitude and phase shift paths connecting $\mathrm{Ni}$ and first two nearest neighboring atoms (O and $\mathrm{Ni}$ ) were calculated on $\mathrm{NiO}$ structure using a FEFF6 code.

\section{Results}

\subsection{Materials characterization by XRD, TEM, TG-DSC-MS and UV-vis-NIR spectra}

Fig. 1 shows the synchrotron radiation XRD patterns of VSB-1 before and after calcination (The laboratory diffractometer data was presented in the Supporting Information of Fig. S1). The diffraction peaks were in line with the reference XRD data of VSB-1[10] which was transformed to the wavelength of synchrotron radiation. It is found the peak intensities of calcined sample decreased. The main characteristic peaks were marked with miller index crystal surfaces in Fig. 1. Meanwhile, the XRD patterns of both the as-synthesized VSB-1 and calcined VSB-1 demonstrated the good match with the reference data, which means the crystallite structure remains after calcination. Quantitative analysis indicated that cell parameters were changed from $19.741 \AA \times 4.998 \AA$ to $19.654 \AA \times 4.981 \AA(\mathrm{a} \times \mathrm{c})($ Cell refinement report was presented in the Supporting information). HRTEM images of VSB-1 before and after calcination (S.I., Fig. S2) also showed that the channels with a diameter of about 1.23 $\mathrm{nm}$ were well ordered, thus providing direct evidence for the nanoporous structure of VSB-1 before and after calcination.[11] The stability of VSB-1 during thermal treatment has been reported in the temperature range from room temperature to $1150^{\circ} \mathrm{C}$.[1] The calcination temperature was set to be $450^{\circ} \mathrm{C}$ in the present study because the crystallite structure at this temperature underwent a significant change in cell parameter but still remains in VSB-1. Based on this change, the local structure was investigated insight into the local environment of nickel in VSB-1 before and 
after calcination.

The TGA/DTG-DSC-MS curves are shown in Fig. 2. It can be seen from Fig. 2a that the decomposition of VSB-1 can be divided into three temperature regions corresponding to the loss of the groups identified from the corresponding ion currents of MS data from Fig. 2b. The endothermic peak in the region of $25-250^{\circ} \mathrm{C}$ is due to desorption of water molecules and departure of hydroxyl groups (weight loss $\sim 8.6 \%$ ); that in the region of $250-450^{\circ} \mathrm{C}$ for the loss of amine moieties (weight $\sim 3.0 \%$ ), and $450-850^{\circ} \mathrm{C}$ for the rest weight loss of $18 \%$. All these assignments are in consistence with the previous reports about thermal stability of VSB-1 materials.[1, 11] However, the weight loss from the temperature over $450^{\circ} \mathrm{C}$ was not identified to any groups lost from the VSB-1(As-synthesized) in the previous literature. In this investigation, the loss of $\mathrm{F}$ ions could be found from $420^{\circ} \mathrm{C}$, as seen from the ion currents of $\mathrm{F}$ ions (M19) and HF (M20) in Fig. 2b. Chemical analysis shows that Ni/F atomic ratio in VSB-1(As-synthesized) is 18.0:9.2, whereas that in VSB-1(Calcined) is 18.0:5.3. Based on the chemical analysis, F content in VSB-1(Calcination) reduced about $42.4 \%$ compared with that in VSB-1(As-synthesized).

UV-vis absorption spectra of VSB-1 before and after calcination between 350 and $550 \mathrm{~nm}$ measured at room temperature are shown in Fig. 3. The absorption band of VSB-1 dried at $80^{\circ} \mathrm{C}$ was found to be at about $415 \mathrm{~nm}$, which is due to the electron transition of $\mathrm{Ni}-\mathrm{O}$ and claimed to be the characteristic absorption of the octahedral symmetry in coordination environment. $[10,21]$ The red-shift occurred for this band from 415 to $427 \mathrm{~nm}$ when the sample was calcined at $450^{\circ} \mathrm{C}$ for 6 hours, which is in agreement with the previous reports and ascribed to the condensation of $\mathrm{OH}$ at higher temperatures leading to a weaker, coordination symmetry transformed from six-coordinated octahedral to five- and/or four-coordinated polyhedral or the mixture of them.[22]

\subsection{Coordination environment detected by XAS}

Fig. 4 presents the XANES and EXAFS data for VSB-1 before and after calcination, as well as the reference NiO. Both VSB-1(As-synthesized) and VSB-1(Calcined) showed similar edge positions and their XANES spectra are similar 
to those in $\mathrm{NiO}$ (Fig. 4). The only major difference was in the white line intensity. EXAFS data in k-space also showed more strong amplitude of VSB-1(As-synthesized) than that of VSB-1(Calcined) (Fig. 4c and Fig. 4d). Both XANES and EXAFS data indicate that the coordination numbers of $\mathrm{Ni}$ first nearest neighbors reduced by calcination. The main observation from XANES data is that the main peak corresponding to the $1 \mathrm{~s}-4 \mathrm{p}$ transition (the "white line") of Ni K-edge is higher in intensity in the as-synthesized sample compared to both the calcined sample and $\mathrm{NiO}$ reference, indicating that the chemical state of $\mathrm{Ni}$ in the as-synthesized sample is the most oxidized. The intensity of the first and second nearest neighboring peaks in the $\mathrm{Ni}$ K-edge EXAFS data in r-space are larger in the as-synthesized sample, also consistent with increased coordination of $\mathrm{Ni}$ by its neighbors, on average, in the as-synthesized sample compared to the calcined one (and $\mathrm{NiO}$ ).

To quantitatively analyze the local structure of nickel in VSB-1 before and after calcination, data analysis of EXAFS spectra (Fig. 5) was performed using IFEFFIT package.[20, 23, 24] Theoretical photoelectron scattering amplitudes and phase shifts of Ni-O contribution were generated by FEFF6 software[25] using crystal structure of $\mathrm{NiO}$ (S.I., Fig. S3). In this analysis, we haven't attempted to discriminate between $\mathrm{Ni}-\mathrm{O}$ and Ni-F contributions at the first nearest neighbor positions because $\mathrm{O}$ and $\mathrm{F}$ are neighbors in Periodic Table. The passive electron reduction factor was fixed to 1.01 , as found from the fit to the reference compound $(\mathrm{NiO})$. All fitting parameters for all fitted shells, including those for the fits to the $\mathrm{NiO}$ standard are listed in Table 1. The results obtained for the VSB-1(As-synthesized) demonstrate that each $\mathrm{Ni}$ ion in the nearest coordination shell is surrounded, on average, by $7.2 \pm 0.5$ neighbors with a coordination distance $2.049 \pm 0.006 \AA$ and mean squared bond length disorder $\sigma^{2}=$ $0.008 \pm 0.001 \AA^{2}$; for VSB-1(Calcined), each Ni ion in the nearest coordination shell is surrounded on average by $6.4 \pm 0.5$ neighbors with a coordination distance $2.034 \pm 0.007 \AA$ and mean squared bond length disorder $\sigma^{2}=0.008 \pm 0.001 \AA^{2}$. Because the disorder parameter does not change, within the experimental uncertainties, the changes in the coordination numbers are not likely to be caused by the correlation between the fitting parameters but reflect real changes in the local atomic 
environment around $\mathrm{Ni}$ between the two samples.

\section{Discussion}

From the XRD and TEM characterization, nanoporous material of VSB-1 was successful synthesized before and after calcination, and its structure was kept but with a considerable unit cell shrinkage to some extent. UV-vis absorption spectra of VSB-1 before and after calcination show the coordination environment changes when VSB-1(As-synthesized) was calcined. It was evidenced that octahedral symmetry changes to a lower coordination system, but still kept as octahedral system. It was also explained that the color of the material became brown from yellowish green at room temperature after calcination at $450^{\circ} \mathrm{C}$. However, there is no more accurate coordination numbers that could be obtained directly from UV-vis absorption spectra.

The framework of VSB-1 consists of linked $\mathrm{PO}_{4}$ tetrahedra and $\mathrm{NiO}_{6}$ octahedra. The main channels are bounded by 24 units.[1, 2, 26] The complex structure of VSB-1 led to the determination of an average structure, leaving the finer details still unknown.[26] As pointed in Scheme 1, VSB-1 consists of ordered sites and disordered sites.[2] Statistically, the ordered sites and disordered sites is fifty-to-fifty.

EXAFS results demonstrated the difference in coordination numbers for VSB-1 before and after calcination. However, neither EXAFS nor XANES can directly observe $\mathrm{F}$ substituting for $\mathrm{O}$ or entering the first coordination sphere, in addition to $\mathrm{O}$, because $\mathrm{F}$ and $\mathrm{O}$ are neighbors in the Periodic Table. EXAFS are consistent with the model in which $\mathrm{F}$ enters the first shell because the coordination number of all nearest neighbors to $\mathrm{Ni}$ increases, assuming that all the nickel atoms are with a basic unit of $\mathrm{NiO}_{6}$.

In the as-synthesized material, VSB-1(As-synthesized), the coordination number of Ni-first neighbors is consistent with $7.2 \pm 0.5$, which means that majority of $\mathrm{Ni}$ atoms see a F atom which is allowed by VSB-1 structure. After calcination the coordination number of VSB-1 (Calcined) drops to $6.4 \pm 0.5$ which means that, on average, only half of $\mathrm{Ni}$ atoms see $\mathrm{F}$, the rest are in octahedral coordination. The latter statement is only approximate because of the relatively large experimental error bar. 
Still, the decrease of the total number of Ni-O/F neighbors is evident and this decrease is not caused by a correlation of fitting parameters (the bond length disorder of $\mathrm{Ni}-\mathrm{O} / \mathrm{F}$ bonds remains constant, within the error bars, between the both measurements). Such interpretation is in agreement with the chemical analysis, where about half of $\mathrm{F}^{-}$ions in the as-synthesized VSB-1 were removed by calcination.

The local environment change of nickel in VSB-1 before and after calcination was shown in Scheme 1. Based on this investigation, the loss of half of the $\mathrm{F}^{-}$ions in VSB-1(As-synthesized) might be responsible for the unit cell shrinkage. It should be noted the loss of $\mathrm{F}$ ions could take place from ordered nickel sites and/or disordered sites.

\section{Conclusion}

The loss of $\mathrm{F}^{-}$ions was found when VSB-1 open framework material was calcined at $450^{\circ} \mathrm{C}$ in air for $6 \mathrm{~h}$ for releasing the pore system. It is closely related to the local coordination environment change of nickel, based on the XANES and EXAFS results. Analysis of the coordination numbers of nickel nearest neighbors for VSB-1(As-synthesized) and VSB-1(Calcined) led to a conclusion that F atoms were likely to have been coordinated to nickel and that approximately half of $\mathrm{F}^{-}$ions were removed by calcination. 


\section{Acknowledgments}

The authors acknowledge support from China Petrochemical Technology Company, Ltd. Use of the NSLS is supported by the U.S. Department of Energy, Office of Science, Office of Basic Energy Sciences, under Contract No. DE-AC02-98CH10886. Beamline X19A at the NSLS was supported in part by the Synchrotron Catalysis Consortium through the U.S. Department of Energy Grant No DE-FG02-05ER15688. The authors acknowledge Drs. Qi Wang, Nebojsa Marinkovic and Syed Khalid for assistance with synchrotron measurements. The authors are grateful to Dr. Rongwei Wang for useful discussions. The authors are grateful to Dr. Nick Greeves for using $\begin{array}{llll}\text { VSB-1 } & \text { structure } & \text { data } & \text { file }\end{array}$ http://www.chemtube3d.com/solidstate/SS-Z-VSB.htm. 


\section{References:}

[1] N. Guillou, Q. Gao, M. Nogues, R.E. Morris, M. Hervieu, G. Férey, A.K. Cheetham, C. R. Acad. Sci. Paris, t. 2, Série II c, 2 (1999) 387.

[2] J. Chang, S. Park, Q. Gao, G. Ferey, A.K. Cheetham, Chem. Commun., (2001) 859.

[3] J. Chang, J. Hwang, S.H. Jhung, S. Park, G. Férey, A.K. Cheetham, Angew. Chem. Int. Ed., 43 (2004) 2819.

[4] L. Xie, Q. Gao, X. Su, P. Wang, J. Shi, Micropor. Mesopor. Mater., 75 (2004) 135.

[5] X. Wang, Q. Gao, Mater. Lett., 59 (2005) 446.

[6] X. Wang, Q. Gao, Nanosci. Technol., 121-123 (2007) 479.

[7] T.W. Kim, E. Oh, S. Jhung, J. Chang, S. Hwang, J. Nanosci. Nanotechnol., 10 (2010) 240.

[8] X. Wang, Q. Gao, Y. Zhang, L. Shen, G. Sheng, Rare Metal Mat. Eng., 37 (2008) 415.

[9] Z. Chen, Q. Gao, Solid State Phenom., 121-123 (2007) 453.

[10] X. Wang, Q. Gao, C. Wu, J. Hu, M. Ruan, Micropor. Mesopor. Mater., 85 (2005) 355.

[11] S. Nie, Y. Hu, L. Song, S. He, D. Yang, Polym. Adv. Technol., 19 (2008) 489.

[12] S. Nie, L. Song, Q. Tai, J. Zhan, H. Lu, Y. Hu, Polym. -Plast. Technol., 48 (2009) 464.

[13] X. Wang, Q. Gao, J. Lumin., 132 (2012) 439.

[14] Z. Chen, Q. Gao, C. Wu, M. Ruan, J. Shi, Chem. Commun., (2004) 1998.

[15] P.M. Forster, J. Eckert, J. Chang, S. Park, G. Férey, A.K. Cheetham, J. Am. Chem. Soc., 125 (2003) 1309.

[16] D.H. Kim, J. Szanyi, J.H. Kwak, X. Wang, J.C. Hanson, M. Engelhard, C.H.F. Peden, J. Phys. Chem. C, 113 (2009) 7336.

[17] S.H. Jhung, J. Chang, J.W. Yoon, J.M. Grenèche, G. Férey, A.K. Cheetham, Chem. Mater., 16 (2004) 5552.

[18] M. Newville, J. Synchrotron Radiat., 8 (2001) 322.

[19] B. Ravel, M. Newville, J. Synchrotron Radiat., 12 (2005) 537.

[20] M. Newville, P. Līviňš, Y. Yacoby, J.J. Rehr, E.A. Stern, Phys. Rev. B, 47 (1993) 14126.

[21] Á. Kukovecz, Z. Kónya, D. Mönter, W. Reschetilowski, I. Kiricsi, J. Mol. Struct., 563-564 (2001) 403.

[22] X. Zhao, M. Du, Y. Wang, X. Bu, J. Mol. Struct., 687 (2004) 119.

[23] M. Newville, J. Synchrotron Radiat., 8 (2001) 322.

[24] B. Ravel, M. Newville, J. Synchrotron Radiat., 12 (2005) 537.

[25] S.I. Zabinsky, J.J. Rehr, A. Ankudinov, R.C. Albers, M.J. Eller, Phys. Rev. B, 52 (1995) 2995.

[26] M. Colmont, O. Terasaki, J. Solid State Chem., 180 (2007) 885. 


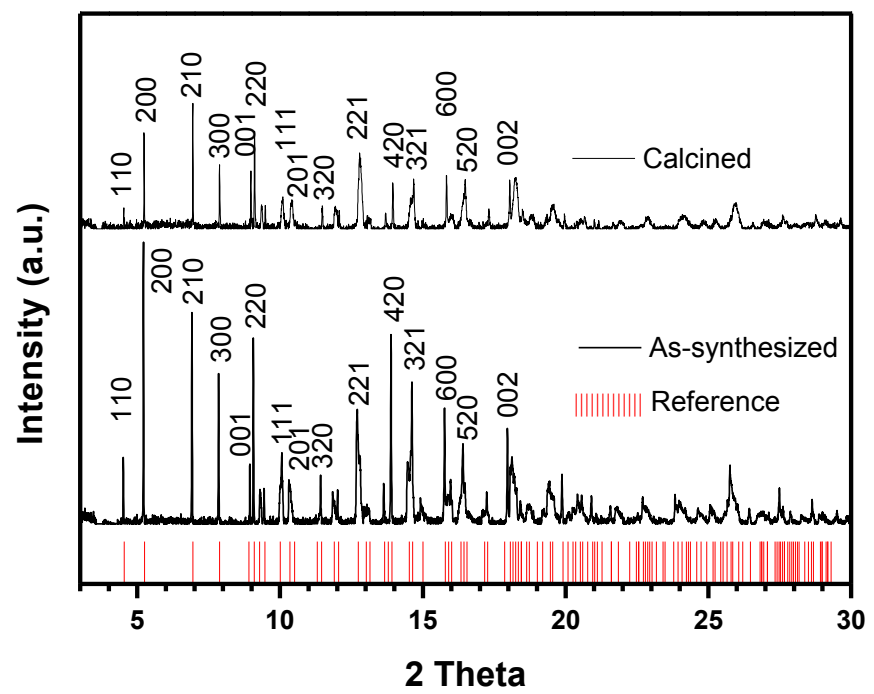

Fig. 1. SR-XRD patterns of VSB-1(As-synthesized) and VSB-1(Calcined) at $450^{\circ} \mathrm{C}$ in air. 


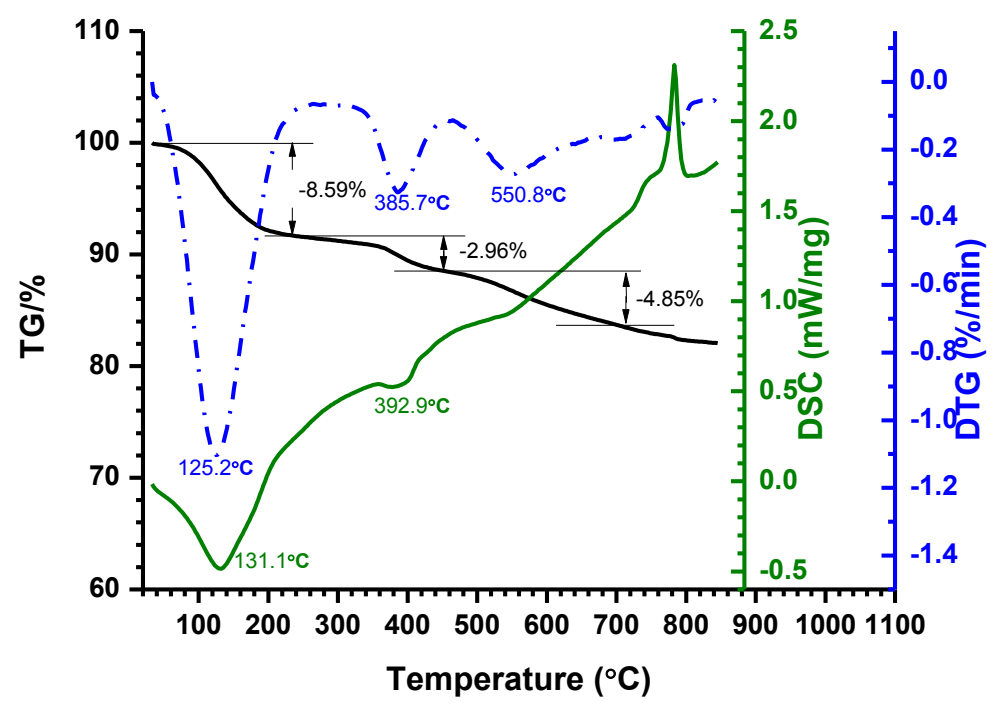

(a)

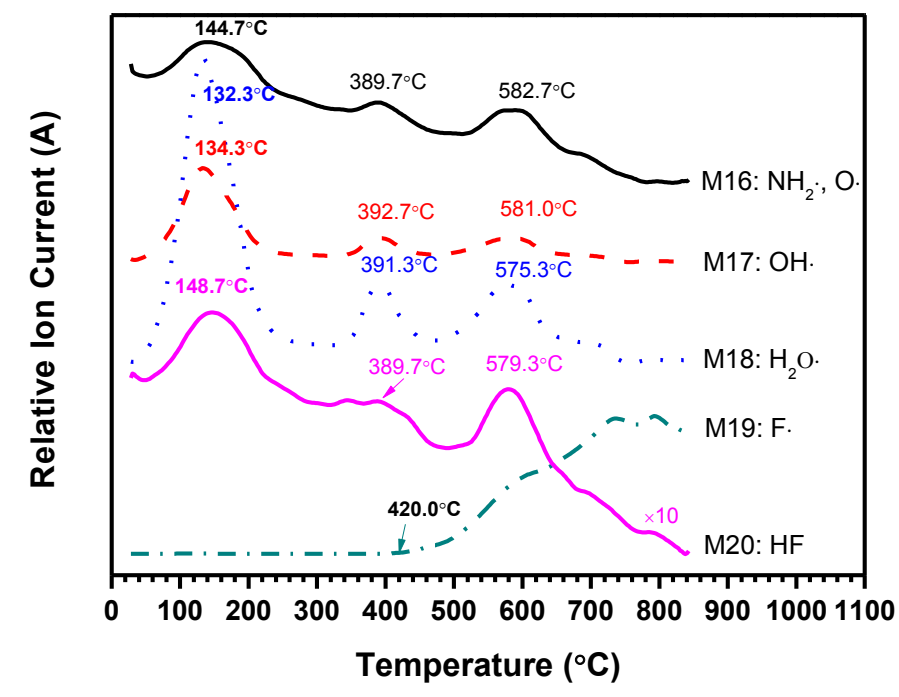

(b)

Fig. 2. TG/DTG-DSC-MS curves of VSB-1(As-synthesized) in airflow: (a) TG/DTG-DSC curves, (b) MS curve. 


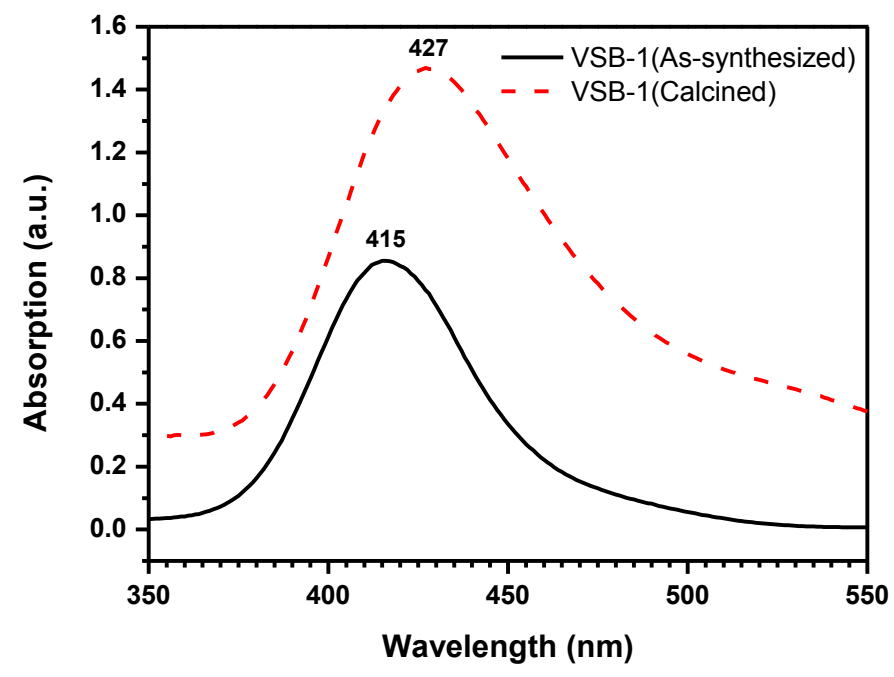

Fig. 3. UV-vis-NIR absorption spectra of VSB-1(As-synthesized) and VSB-1(Calcined) between 350 and $550 \mathrm{~nm}$ 


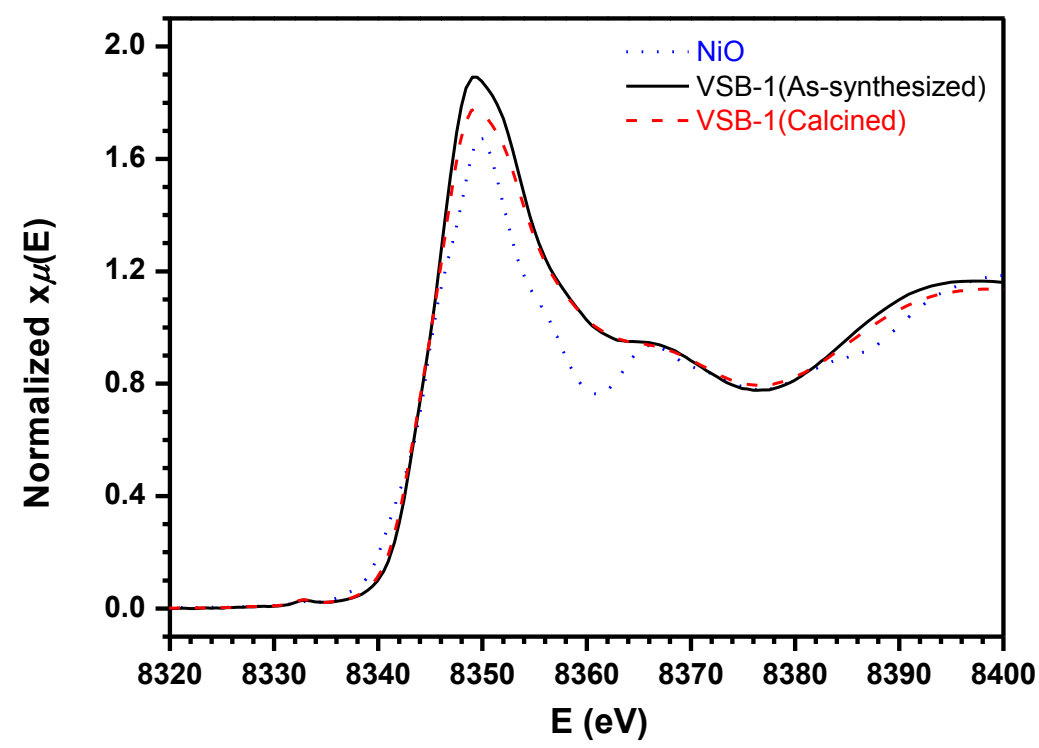

(a)

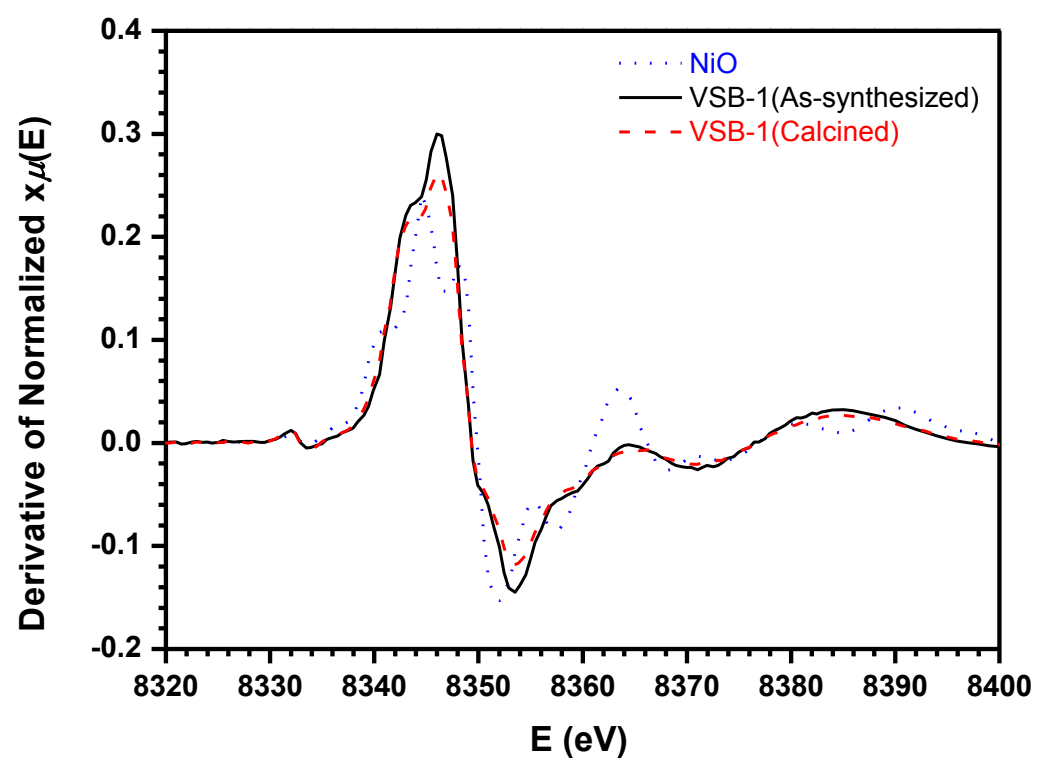

(b) 


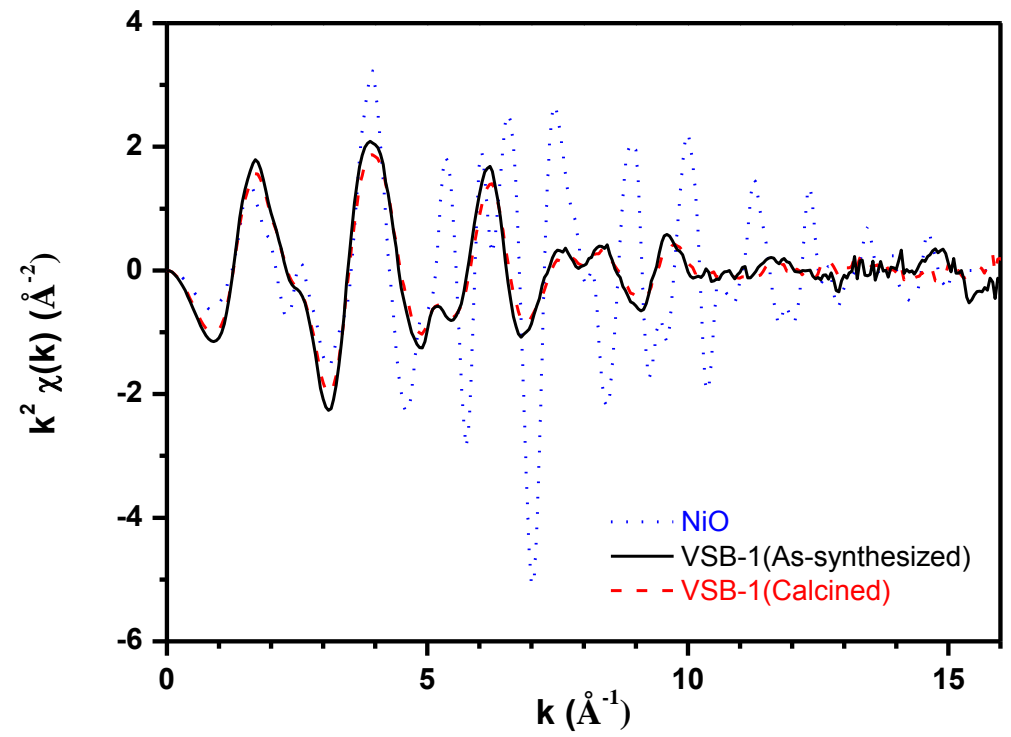

(c)

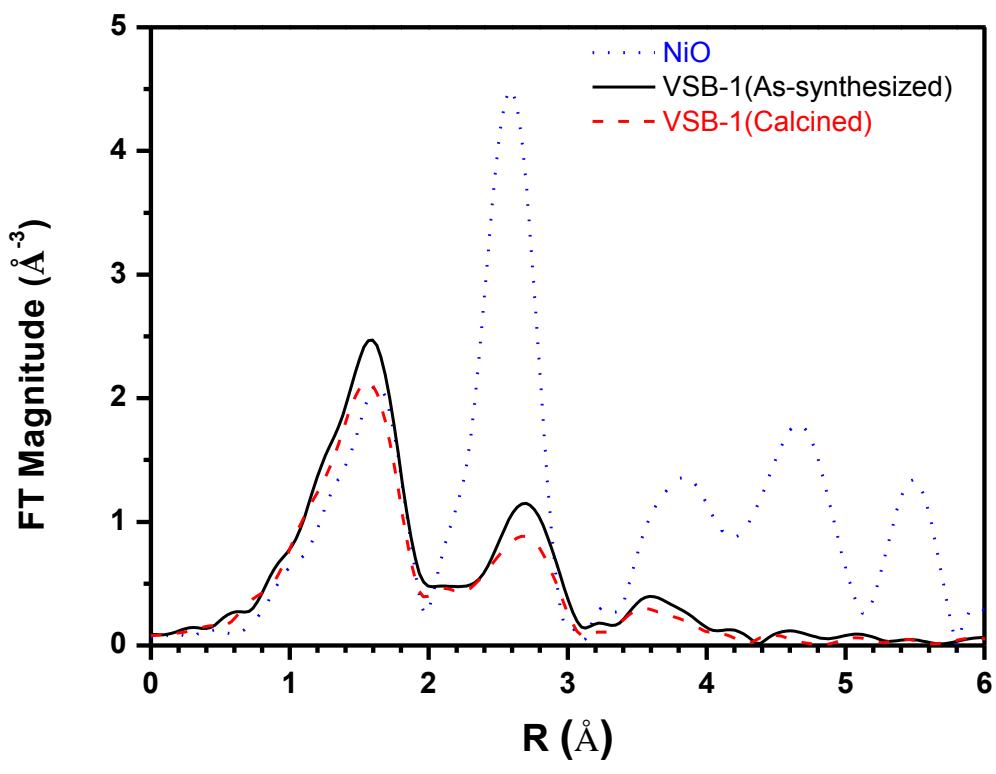

(d)

Fig. 4. XANES and EXAFS structure changes for VSB-1(As-synthesized), VSB-1 (Calcined) and NiO: (a) XANES spectra, (b) Derivative of XANES spectra, (c) EXAFS data in k-space (k-weight $=2$ and k-range $\left.=2-15 \AA^{-1}\right)$, (d) corresponding Fourier transform magnitudes in real space. 


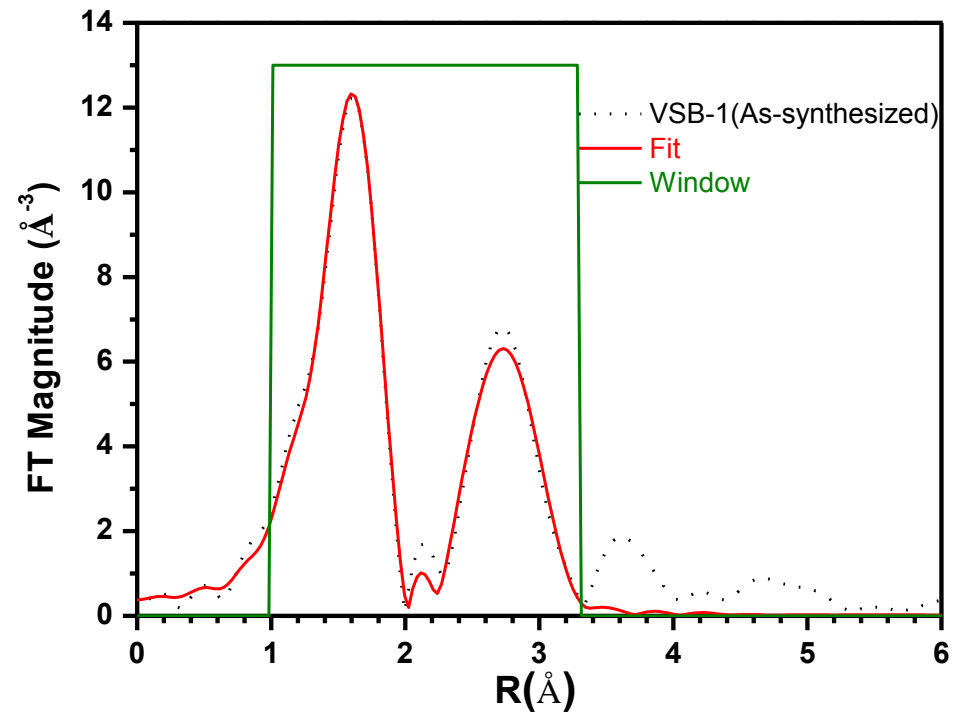

(a)

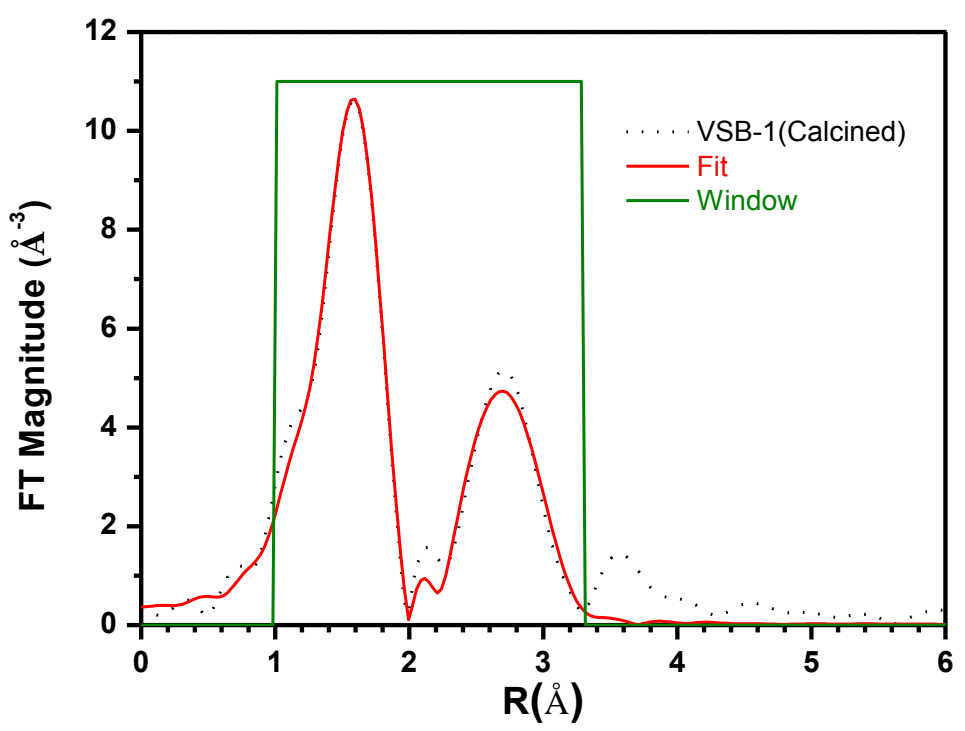

(b)

Fig. 5. $k^{2}$-weighted EXAFS data (k-range $\left.=2-16 \AA^{-1}\right)$ and the fitting curve in r-space for nickel K-edge of: (a) VSB-1(As-synthesized) and (b) VSB-1(Calcined). 


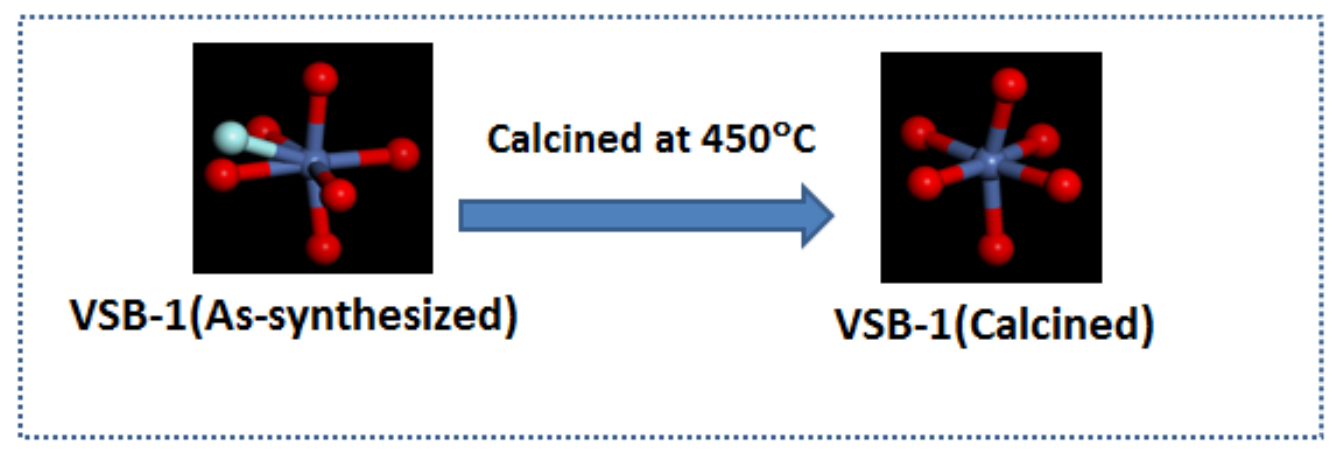

Scheme 1. The local environment change of nickel in VSB-1 before and after calcination. 
Table 1

Fitting parameters to NiO, VSB-1(As-synthesized) and VSB-1(Calcined)

\begin{tabular}{|c|c|c|c|c|c|c|}
\hline \multirow[t]{2}{*}{ Parameters } & \multicolumn{2}{|l|}{$\mathrm{NiO}$} & \multicolumn{2}{|c|}{$\begin{array}{l}\text { VSB-1 } \\
\text { (As-synthesized) }\end{array}$} & \multicolumn{2}{|l|}{$\begin{array}{l}\text { VSB } \\
\text { (Calcined) }\end{array}$} \\
\hline & $\mathrm{Ni}-\mathrm{O}$ & $\mathrm{Ni}-\mathrm{Ni}$ & $\mathrm{Ni}-\mathrm{O}$ & $\mathrm{Ni}-\mathrm{Ni}$ & $\mathrm{Ni}-\mathrm{O}$ & $\mathrm{Ni}-\mathrm{Ni}$ \\
\hline$S_{0}^{2}$ & $1.01(6)$ & - & 1.01 & 1.01 & 1.01 & 1.01 \\
\hline $\mathrm{N}$ & 6 & 12 & $7.2(5)$ & 7.7(1.4) & $6.4(5)$ & 7.7(1.9) \\
\hline $\mathrm{R}$ & $2.083(9)$ & $2.948(4)$ & $2.049(6)$ & $3.088(12)$ & $2.034(6)$ & $3.072(16)$ \\
\hline$\Delta \mathrm{E}_{0}$ & 1.92 & $-0.1(7)$ & $1.3(8)$ & 6.1(1.6) & $0.8(9)$ & $5.8(2.0)$ \\
\hline$\sigma^{2}$ & $0.0058(8)$ & $0.0060(3)$ & $0.0079(8)$ & $0.0137(16)$ & $0.0083(10)$ & $0.0165(23)$ \\
\hline
\end{tabular}

"Uncertainties in the last one or two significant digits are given in parentheses 